\title{
Las microasociaciones españolas/ gallegas en Río de Janeiro (1900-1940): florecer y silencio en el escenario de la Guerra Civil española
}

\section{Érica Sarmiento}

Universidade do Estado do Rio de Janeiro, Brasil / Laboratório de Estudos de ImigraçãoLABIMI/UERJ/ Fundação de Amparo a Pesquisa do Estado do Rio de Janeiro, Brasil

Fecha de recepción: 8 de abril de 2020. Fecha de aceptación: 9 de junio de 2020.

\section{Resumen}

El artículo tiene como objetivo contribuir, de manera introductoria, a los estudios de las asociaciones gallegas de alcance microterritorial en Río de Janeiro, utilizando cono fuente principal la correspondencia entre el Consulado Español y las asociaciones españolas/gallegas ubicadas en Río de Janeiro, en la década de 1930, período correspondiente al de la Guerra Civil española y al gobierno de Getúlio Vargas, con el inicio del Estado Novo, en 1937. A partir de la interpretación de las fuentes obtenidas en el Archivo General de la Administración, del Ministerio de Asuntos Exteriores, fue posible formular argumentos sobre algunas de las microasociaciones pertenecientes a la comunidad gallega de las primeras décadas del siglo XX y que supuestamente desaparecieron en una etapa temprana. Investigamos la funcionalidad de algunas de las sociedades microterritoriales, la importancia de la escala en los estudios migratorios, la percepción de las redes sociales, así como las lagunas evidenciadas por la historiografía sobre las sociedades gallegas y españolas en general.

Palabras claves: asociacionismo, microasociaciones gallegas, Río de Janeiro, Guerra Civil española, Estado Novo brasileño. 


\title{
Spanish / Galician micro associations in Rio de Janeiro (1900- 1940): flourishing and silence in the context of the Spanish Civil War
}

\begin{abstract}
The article aims to contribute, in an introductory way, to the studies of Galician associations of microterritorial scope in Rio de Janeiro, using as main source the correspondence between the Spanish Consulate and the Spanish / Galician associations located in Rio de Janeiro, in the 1930s, period corresponding to that of the Spanish Civil War and the government of Getúlio Vargas, with the beginning of the Estado Novo, in 1937. From the interpretation of the sources raised in the Archivo General de la Administración, belonging to the collection of the Spanish Ministry of Foreign Affairs, it was it is possible to formulate arguments about some of the microassociations belonging to the Galician community of the first decades of the 2oth century and which supposedly disappeared at an early stage. We investigate the functionality of some of the microterritorial societies, the importance of scale in migratory studies, the perception of social networks, as well as the gaps evidenced by historiography about Galician and Spanish societies in general.
\end{abstract}

Keywords: associationism, Galician micro-associations, Rio de Janeiro, Spanish Civil War, Brazilian Estado Novo.

\section{As microassociações españolas/galegas no Rio de Janeiro (1900-1940): florescer e silêncio no cenário da Guerra Civil espanhola}

\section{Introdução}

$\mathrm{O}$ artigo a ser apresentado pretende contribuir, de forma introdutória, para o estudo do associativismo galego, especificamente o microterritorial, localizado na cidade do Rio de Janeiro, durante o período da Grande Imigração de massas até o final da Guerra Civil espanhola. Um período, como diz o título do artigo, de florescer e de ocaso de algumas associações que fizeram parte do cenário da imigração galega na América.

O tema do associativismo galego é um velho conhecido da historiografia das migrações. Muito se tem escrito nas últimas décadas sobre a experiência associativa galega, merecendo especial atenção de historiadores que debruçaram parte de suas obras à temática. Conforme Alejandro Fernández bem salientou em seu artigo intitulado "Historiografía das asociacións 
galegas: o caso arxentino e algunhas comparacións latino-americanas", é provável que não exista na América Latina uma coletividade tão ampla e multiforme como a galega, cuja experiência associativa abarca todos os níveis geográficos, passando pelos grandes centros regionais, locais ou paroquiais. Entretanto, apesar da conhecida existência das associações galegas e de sua diversidade, em diferentes períodos das imigrações atlânticas, Fernández sinaliza:

Em cidades como Buenos Aires e Montevideo ou A Habana, a riqueza e variedade das fontes emanadas das asociacións galegas ou españolas facilitaron o traballo dos historiadores, o cal contrasta coa escassez e a fragmentación da devandita documentación noutros centros urbanos latino-americanos, incluso nalguns moi grandes que contaron cunha colectividade galega ou española relativamente nutrida como, por exemplo, São Paulo (Fernández, 2011: 143-144).

A ausência de documentação considerada substancial para o estudo das microassociações galegas tais como as atas, os livros de sócios ou a imprensa étnica contribuiu para que existisse uma lacuna em relação ao caso do Brasil, principalmente dos fluxos migratórios correspondentes às cidades de grande recepção de espanhóis e galegos como foi o caso do Rio de Janeiro ou de São Paulo. Sem essa documentação, torna-se muito difícil a descrição do mundo societário e, por exemplo, a construção de tipologias da coletividade associada em base às informações contidas nos livros de registros de sócios.

Em contraste com os estudos das microassociações galegas no Brasil, nos deparamos com o caso argentino, indiscutivelmente superior em quantidade e sistematização das variáveis. A concentração de pesquisas, no caso argentino, deve-se muito ao fato de que, nas últimas décadas, tanto a imigração espanhola "genérica"1 como os fluxos migratórios procedentes principalmente da região da Galícia, contam, na atualidade, com uma importante massa crítica direcionada aos estudos de caso, que possibilitaram a compreensão dos fatores macroestruturais e microssociais do fenômeno, além do conhecimento da inserção espacial e profissional dos imigrantes hispanos (principalmente em Buenos Aires e na sua periferia).

Conhecido e muito estudado pela historiografia contemporânea, o associativismo galego em Buenos Aires gerou uma forte rede de solidariedade que incentivou a circulação de ideias, através dos periódicos, e também

1 Podemos citar algumas obras como a de Fernández y Moya (1999); Moya (2004); Sánchez Alonso (1992). 
o envio de remessas para a sociedade de origem. Os galegos desenvolveram na Argentina praticamente todas as possibilidades de associativismo, combinando a procedência geográfica (regional, provincial, local, comarcal ou paroquial) com os objetivos específicos que cada uma possuía (mutualistas, médicas, beneficência, culturais, recreativos, desportivos, políticos, etc. Somente na capital argentina surgiram mais de 327 associações entre os anos de 1904 e 1936, chegando a contabilizar 476 no conjunto total do país entre 1901 e 1933. Os trabalhos desenvolvidos na Argentina deixam em evidência o potencial ainda não esgotado da documentação ligada às associações, como se pode observar ao analisar a composição do Arquivo da Federação de Associações Galegas da República Argentina (Farías, 2011). Esses estudos, já consolidados, servem como um importante referencial metodológico e, também, na análise de fontes, além de nos auxiliar a repensar o caso brasileiro, a partir de um viés comparativo. ${ }^{2}$

A partir do levantamento de fontes localizadas no Archivo General de la Administración, na cidade de Alcalá de Henares, e pertencentes ao acervo do Ministério de Assuntos exteriores espanhol, foi possível formular argumentos acerca de algumas das associações pertencentes à coletividade galega das primeiras décadas do século XX e que supostamente desapareceram de forma precoce. A partir das correspondências trocadas entre o Consulado Espanhol do Rio de Janeiro e as associações galegas, a partir do ano de 1932, averiguamos a funcionalidade de algumas das sociedades microterritoriais, a importância da escala nos estudos migratórios, bem como o silencio e suposto desaparecimento das pequenas associações após o término da Guerra Civil espanhola. ${ }^{3}$

Apesar de todas as dificuldades que a escassez ou inexistência de fontes representa, podemos afirmar que existiu sim um microassociativismo galego no Rio de Janeiro, que se manteve ativo nas primeiras décadas do século $\mathrm{XX}$, e com interlocução com o consulado espanhol dessa cidade. E é através dessas fontes, e amparados por nossos estudos anteriores da coletividade galega no Rio de Janeiro, que daremos a conhecer algumas das associações, extraindo as primeiras e incipientes conclusões sobre a temática.

\footnotetext{
2 Esse estudo comparado encontra-se em Sarmiento (2018).

3 Devido a limitações impostas ao tempo de pesquisa e por normas do Archivo General de la Administración, ao não estar permitida a digitalização dos documentos, somente foi possível levantar algumas pastas relacionadas às associações cariocas do acervo que compreende o período de 1932 a 1936.
} 


\section{O Florescer e o silêncio das microassociações}

É importante salientar, antes de iniciarmos com o estudo das fontes, que para compreender a realidade das microassociações foi necessário o cruzamento entre fontes de diferentes naturezas. Além do acervo do Archivo General de la Administración, pesquisamos também a documentação da polícia política, localizada no Arquivo Público do Estado do Rio de Janeiro, abarcando o período que vai da década de 1930 a 1950. As fontes localizadas no Arquivo de Alcalá de Henares, sem dúvida, abriram novos horizontes na temática do associativismo galego, entretanto a documentação por si só, é insuficiente para compreender alguns aspectos da coletividade galega no Rio de Janeiro. Por exemplo, nas correspondências trocadas entre o consulado espanhol do Rio de Janeiro e as associações, menciona-se, em mais de uma ocasião, o envio de atas e de livros de sócios, porém as mesmas não se encontravam no acervo documental. Convém ressaltar que encontramos somente um livro correspondente aos estatutos entre toda a documentação levantada.

A documentação do Arquivo Público do Estado do Rio de Janeiro, ao ser constituída por fontes nominativas, ou seja, que identificam o sujeito, nos possibilita encontrar muitos imigrantes galegos num cenário de perseguição àqueles estrangeiros vinculados a determinadas ideologías políticas, no contexto de pós-guerra. O cruzamento das fontes nos auxilia a compreender a mobilização de muitas lideranças galegas, num recorte cronológico onde já perdemos a pista de todas as sociedades microterritoriais galegas no Rio de Janeiro, a partir de 1939.

Para começar, pensaremos a questão das microterritorialidades, a partir das associações étnicas de âmbito micro, que remetem a estratégias de uso, apropriação e defesa de pequenas porções do espaço urbano por parte de grupos sociais, muitas vezes invisibilizados, mas que, subterraneamente, também atuam na cidade, tanto material quanto imaterialmente, na medida em que produzem espaços e formas culturais de convivências específicas. Nessa perspectiva, tocaremos em alguns pontos que consideramos centrais e que assinalam alguns dos desafios no delineamento da temática, por exemplo a questão da escala e das redes de vizinhanças. Trabalharemos com a possibilidade de analisar algumas variáveis, que fazem parte do estudo do associativismo, como as necessidades de sua coletividade, o vínculo com a sociedade de origem, sempre levando em consideração que os tecidos associativos possuem dimensões complexas e plurais. Por isso, devemos levar em consideração, de antemão, que o perfil social de determinada entidade nem sempre é o representativo do coletivo. 
Na documentação analisada, no Arquivo geral da Administração, encontramos o total de 13 associações espanholas que se correspondiam com as autoridades consulares, mas, respeitando a temática da pesquisa aqui apresentada, vamos nos ater às sociedades galegas, de âmbito microterritorial. São elas: Sociedad Hijos del Districto de Arbo (província de Pontevedra); Sociedad Protectora Hijos de Cabeiras (município de Arbo, fundada em 1925); ${ }^{4}$ Aurora del Porvenir (da paróquia de Tomiño, província de Pontevedra, registrada no ano de 1912); Sociedad Pro-Santa Bárbara ${ }^{5}$ (da paróquia de San Jorge de la Salceda, província de Pontevedra); Sociedad Agrícola y Industrial Luz de los Rivartemes, fundada no ano de 1913, do Concelho de As Neves (província de Pontevedra); Hijos de Picoña (do Concelho de Salceda de Caselas, província de Pontevedra); ${ }^{6}$ Sociedad Hijos de Rubiós (do concelho de As Neves, província de Pontevedra), criada em 1927, com o total de 36 sócios. $^{7}$

De todas as associações mencionadas acima, a Aurora del Porvenir foi a única já analisada, mesmo que de forma superficial, por essa autora (Sarmiento, 2018). Foi fundada no ano de 1912 e seu registro encontra-se localizado no Arquivo Nacional, no Rio de Janeiro. A associação foi criada com o fim de "construir patrimônio para fundar em Tomiño, na província de Pontevedra, uma escola prática onde possam gratuitamente receber instrução moral e intelectual". ${ }^{8}$ A Aurora del Porvenir encontra-se na região denominada "Baixo Minho", zona fronteiriça a Portugal, de intensa imigração ao Brasil, principalmente, ao Rio de Janeiro. ${ }^{9}$ Essa escola forma parte das chamadas "escolas de indianos", palavra que define os imigrantes retornados que exerciam um papel socializador e de consciência política do campesinato. A atividade sindical e política terá forte influência na vida da associação. Nada se sabe a respeito desses imigrantes do Concelho de Tomiño, localizado no sul da província de Pontevedra, que resolveram

4 A associação possuia 48 sócios. Informações extraídas do livro de Blanco (2008); Boletín de Emigración, Subdirección General de Emigración, Tomo I, N. 3, 1928, pp., 958-964.

$5 \mathrm{~A}$ informação referente ao munícipio de origem da associação foi retirada do artigo de González Martínez (2008).

6 A associação possuia 45 sócios. Número de sócios retirados da obra organizada por Blanco (2008); Boletín de Emigración, Subdirección General de Emigración, Tomo I, N. 3, 1928, pp., 958-964.

7 A associação possuia 29 sócios. Número de sócios retirados da obra organizada por Blanco (2008); Boletín de Emigración, Subdirección General de Emigración, Tomo I, N. 3, 1928, pp., 958-964.

8 Arquivo Nacional do Rio de Janeiro, $1^{\circ}$ Ofício de Registro de títulos e documentos do Rio de Janeiro. Registro de Sociedades Civis, n. 563.

9 Sobre a distribuição geográfica dos galegos no Rio de Janeiro, ver Sarmiento (2017). 
registrar a sua associação no começo do século XX com o intuito de fundar uma escola no seu município. Os "brasileiros" da Aurora de Porvenir, como são chamados os imigrantes galegos radicados no Brasil, construíram uma importante escola, um patrimônio para a população local, que configuramse como símbolos de um projeto de modernização e democratização para a época. No programa da Associação, incluía-se a laicização da educação, a renovação e a inovação do sistema educativo mediante práticas intuitivas que estimulassem a aprendizagem do aluno (Jorge, 2004).

Ao mencionar a Aurora del Porvenir, não tivemos a intenção de afirmar que as outras associações mencionadas acima fossem desconhecidas completamente da literatura trabalhada até o presente momento. ${ }^{10}$ Sabe-se de sua existência, entretanto não se vai muito além disso, de simples menções. Quando o caso é o Brasil, as lacunas na documentação, como já esclarecemos, vão ser sempre um obstáculo terrível para os estudiosos, mas, percebemos, também, que existe algum distanciamento e certa precaução, por parte dos pesquisadores, em construir novas hipóteses ou, o que significa o mesmo, contestar o que já foi dito sobre a temática. Dessa forma, tentaremos trazer novas contribuições ao não-ditos acerca história dos galegos no Brasil e, especificamente os do Rio de Janeiro, e sugerir novas indagações ao que já foi dito.

Voltando à documentação analisada, vamos pensar, inicialmente, na contribuição desses arquivos no que diz respeito ao movimento associativo, ou seja, a interlocução existente entre as associações, algo sempre muito difícil de captar especialmente entre as sociedades galegas no Brasil e as que se encontram nos países latino-americanos de fala espanhola. Nesse sentido, as correspondências das associações micro no período da Primeira República no Brasil (1889-1930) demostram, ao contrário da afirmação de alguns especialistas, que apoiam a hipótese de que Brasil valoriza mais as instituições regionais e/o nacionais que as de perfil micro, que sim existiu, nas primeiras décadas do século XX, um florescer destas associações, que não somente mantinham filiais em outros países, como também formavam parte da lista de correspondências do consulado español, mantendo-o informado das alterações de seus quadros, da formação das chamadas “juntas directivas”, bem como da participação nas cerimônias da República. Apesar da maioria dessas associações não apresentarem mais do que 50 sócios inscritos, um universo muito modesto e até insignificante se comparado a instituições de âmbito nacional como o Hospital Espanhol ou até mesmo o Centro Galego, ambas no Rio de Janeiro, elas mantinham ativamente sua

10 Pode-se contemplar as citações dessas associações na já mencionada obra organizada por Blanco (2008). 
comunicação com o consulado espanhol, que, por sua vez, solicitava-as em diferentes ocasiões. Em suma, que oficialmente faziam parte da coletividade espanhola no Rio de Janeiro.

Diferentemente de Buenos Aires, que acolheu grande número de microassociações galegas, observamos, para o caso do Rio de Janeiro, a maior presença de um associativismo étnico nacional e regional e a conseguinte preservação de parte de sua documentação nesses espaços nos quais os galegos desenvolveram sua visibilidade como grupo étnico. Entretanto, a permanência e a maior visibilidade dos centros nacionais e regionais não devem silenciar a existência dessas associações micros, que sim tiveram participação na sociedade carioca.

É notória a participação dessas associações, bem como a solicitação das mesmas por parte do Consulado Espanhol do Rio de Janeiro, no período que abrange a Segunda República Espanhola. No ano de 1934, por exemplo, na correspondência enviada pela Sociedade do Distrito de Arbo, informando ao Consulado do Rio de Janeiro sobre a eleição de sua nova junta diretiva, a associação descreve:

Siendo esta Sociedad una de las pequeñas que asiste en este país, mas llegando de concurrir aonde la llamasen cual quier como otra de las que aquí asisten. Estando siempre a sus órdenes que hasta aquí, y mantener las mismas relaciones. ${ }^{11}$

Percebemos nessa correspondência, como a Sociedade do Distrito de Arbo deseja demonstrar a sua força e importância, apesar de reconhecer suas limitações quanto ao número de sócios. Podemos afirmar que o texto consiste em uma narrativa de identidade articulada à exaltação de valores de êxito e integração, características que faziam parte das estratégias das associações étnicas.

No artigo de Hernán Diaz, sobre o estudo de uma associação comarcal galega, denominada "Filhos de Pol e as suas comarcas" (localizadas na província de Lugo), criada no ano de 1925, o autor afirma que os anos da Segunda República espanhola consistiu em um período de enorme entusiasmo societário, apesar na queda dos fluxos migratórios relativos à entrada de imigrantes galegos na Argentina, e de forma, geral, nos otros países americanos receptores de grandes fluxos (Díaz, 2011: 169). Não dispomos da mesma documentação

11 Archivo General de la Administración, DOCUMENTAÇÃO (10)013.001 CAIXA 54-4989, 25 de abril de 1934. Documento transcrito literalmente. Há muitos erros de ortografía na redação. 
utilizada por Díaz em sua pesquisa, como atas e imprensa étnica, mas o que sim podemos constatar, através das correspondências trocadas entre as associações e o Consulado espanhol é que foi um período de intensa comunicação e interesse, por parte do governo espanhol, pelas pequenas sociedades. Elas faziam parte da lista de informações do Consulado Espanhol, juntos com as outras sociedades mais tradicionais e com maior número de sócios, como a Beneficência espanhola e o Centro Galego do Rio de Janeiro.

Um dos exemplos em relação a esse momento de participação da coletividade espanhola do Rio de Janeiro, encontra-se na correspondência do ano de 1934 do Centro Republicano do Rio de Janeiro dirigida ao Cônsul da República, em tons festivos, com objetivo de celebrar os 61 anos de República: ${ }^{12}$

\section{Sr. Eduardo Danis Navarro \\ Distinguido amigo y consocio:}

Con ocasión de la fecha del 11 de Febrero en que se cumplen 61 años de la proclamación de la primera República Española, los miembros de este Centro nos proponemos reunirnos en un almuerzo íntimo en que se congregue la familia republicana española de Rio de Janeiro, y al cual nos es especialmente grato invitarle.

El almuerzo será a las 13 del dia 11 de Febrero, en el Grande Hotel, Largo da Lapa.

Seguros de que nos honrará con su presencia, aprovechamos la oportunidad para reiterarle nuestra alta consideración y aprecio.

Salud y República

Por la Directiva

Segundo Elda González Martínez (2018: 223) a maioria dos centros regionais se mostrou abertamente simpático às ideias republicanas. Para corroborar essa afirmação, a autora cita uma informação enviada em outubro de 1939 pelo cônsul geral, Álvaro Seminario, ao chefe de imprensa e propaganda em Madrid, dizendo:

Quizás sea el Brasil uno de los países de América en el que haya de intensificarse la labor de propaganda españolista, porque los centros españoles, con excepción de la Cámara de Comercio, han quedado em manos de los rojos, y la colonia en su $90 \%$ obedece al ideario republicano-soviético. 
Alguns autores que se dedicaram aos estudos do associativismo espanhol/ galego no Brasil amparam-se, para justificar a invisibilidade das associações comparadas a outros grupos migratórios, em argumentos como a inexistência de uma elite empresarial ou intelectual em contraposição a uma maior frequência de sócios de classes média e baixa, inclusive nas associações regionais; ou que o problema das fontes estaria vinculado à debilidade das próprias associações espanholas em relação à quantidade de membros e aos recursos econômicos que as mesmas poderiam contar (Maciel \& Antonacci, 1990). Segundo Avelina Gallego, em relação à coletividade espanhola no Brasil, de forma geral, esta, ao contrário dos italianos, não contava com um intelectual orgânico e com uma política imigratória que via a imigração como um fator positivo, como um mercado nacional no exterior. Ainda seguindo os argumentos da autora, a emigração espanhola carece de relatórios, crônicas de viagem de autoridades espanholas, artigos na imprensa que relatasse a vida da colônia no Brasil, ademais de contar com uma política que enfatizava as emigrações para as colônias espanholas (Cuba, Argentina, Uruguai) e que estava impregnada por uma mentalidade anti-emigração (Gallego, 1995: 58).

O fato é que existe um consenso na historiografia de que as associações microterritoriais formaram lideranças de cunho mais popular, e, em algumas delas, os setores da classe média compunham seus quadros de diretores (Núñez Seixas, 1998). Nas micro associações aqui apresentadas, a Hijos de Cabeiras, do município de Arbo, fundada no ano de 1925, estava formada por empregados de comércio e não por proprietários. Nesse caso, corroboraria com a inexistência de uma elite intelectual no seio dessas associações, mas, de nenhuma forma, esse argumento deve minimizar a expressividade da coletividade galega e suas ações na sociedade de recepção, como demonstraremos mais adiante.

Outra questão importante que observamos na documentação do Archivo General de la Administración diz respeito ao movimento associativo, ou seja, à interlocução entre as microassociações localizadas em diferentes países. O que nos chamou a atenção na documentação foi encontrar pela primeira vez associações microterritoriais cariocas que mantinham filiais em outros países, como por exemplo, nessa correspondência do ano de 1932:

[...] que nuestra sociedad fue fundada en 16 de Noviembre de 1925 para los fines que marcan nuestros estatutos y los socios que la forman empleados en el comercio y tenemos como Hermanos las fundadas en Buenos Aires y en Cuba y en España, hijos de Cabeiras, Arbo. ${ }^{13}$ 
Notemos que a associação radicada no Brasil constituía-se na principal e as demais foram apresentadas como filiais. Em nenhum dos casos, desafortunadamente, tanto o do Brasil como de Buenos Aires, encontramos, de momento, as atas da sociedade, para realizar um estudo mais pormenorizado dessa pequena associação.

Outro caso a ser destacado é a já mencionada associação Aurora del Porvenir. Nela também aparece a Sub-Directiva em Buenos Aires, na Calle Sarmiento 385 e a outra Sub-Directiva na cidade de Santos, em São Paulo, na Rua Amador Bueno, 189, sendo que a Sucursal estava sediada no município de Tomiño- España. Por último, destacamos a Sociedade Protectora Hijos de Cabeiras, que, em correspondência do dia 3 de outubro de 1932, inicia o documento esclarecendo "sobre a existencia e a importância de sua sociedade" e o conclui explicando:

[...] que os socios que componen actualmente esta sociedad son en número de 45 , todos ellos personas de modesta posición pero de una honradez a toda prueba. En las capitales de Buenos Aires y Habana existen también otras sociedades co-hermanas de la establecida aquí, con los mismos fines y con número de socios más o menos igual a esta. ${ }^{14}$

Vale ressaltar mais uma característica comum no associaitvismo galego: a relação com o lugar de origem e o que isso implica, como os retornos e as remessas. Segundo Núñez Seixas (2000: 24), a interrelação entre a mobilização política e social a escala local na Galícia durante o primeiro terço do século XX e sua transferência para uma parte do coletivo emigrante constituiu-se em um dos principais fatores para compreender o surgimento do associativismo microterritorial. Apesar de Seixas se referir, nesse estudo em específico, às paroquias de Buenos Aires, a regra vale para o caso do Rio de Janeiro, especialmente para as associações Aurora del Porvenir e Sociedad Agrícola y Industrial Luz de los Rivartemes, as únicas das quais dispomos dos estatutos.

A Sociedad Agrícola y Industrial Luz de los Rivartemes foi criada no ano de 1913, sendo seus socios originários do município de As Neves (Pontevedra). Para esse caso, contamos com o livro de regulamento da instituição, documentação que se encontrava juntos às correspondências consulares. A

Sociedades españolas 1932. 
sociedade funcionava com fins mutualistas, oferecendo repatriação para os sócios enfermos ou sem recursos, e o direito a um funeral modesto. ${ }^{15}$

Entre os objetivos da Sociedad Agrícola y Industrial Luz de los Rivartemes estava o de privilegiar o progresso e o desenvolvimento do campo galego, bem como a instrução das suas gentes. Uma parte do rendimento deveria ser para auxiliar a sociedade matriz, que se encontrava na paróquia de Rivarteme. Para ser sócio, deveria ter mais de 14 anos, considerada já idade adulta para imigração, ter bons costumes e pertencer ao concelho de As Neves (Pontevedra), além de residir no Rio de Janeiro e (curiosamente), na cidade de Petrópolis. Pela primeira vez, temos o caso de uma associação microterritorial do Rio de Janeiro que possuía um núcleo em outro município, o que demonstra uma rede migratória dos vizinhos de As Neves que se estendia ao interior do estado.

Está claro que houve um florescer dessas associações, de âmbito microterritorial no Rio de Janeiro, nas primeiras décadas do século XX, como não ocorreu em outros estados brasileiros. Por que, então, houve um silêncio em relação a essas associações quanto a sua existência e a inexistência de sua documentação? É importante compreender a conjuntura histórica em ambos países, tanto o de origem quanto o de recepção, para explicar, em parte, o silêncio em torno a estas sociedades a partir da década de 1940. Por exemplo, uma observação importante, após acompanhar a documentação no período de 1932 a 1936 é que, a partir do ano de 1936, início da Guerra Civil e faltando um ano para o período do Estado Novo no Brasil, o início da ditadura de Getúlio Vargas em 1937, foi possível averiguar que os documentos trocados entre as associações e o consulado espanhol do Rio de Janeiro começaram a assumir outro tom. Devemos levar em conta que no Brasil se começa a observar de forma diferente aqueles espanhóis republicanos e de esquerda, principalmente os que eram sócios do Centro Galego do Rio de Janeiro. Sobre esse contexto, Maria Luiza Tucci Carneiro afirma:

É fato que, entre 1936 e 1939, o tema da Guerra Civil Espanhola
ocupou um lugar privilegiado na grande imprensa brasileira, assim
como na documentação produzida por diplomatas brasileiros em
missão na Espanha e autoridades policiais sediadas no Departamento
Estadual de Ordem Política e Social do Estado de São Paulo-Deops/
SP. Enquanto as notícias sobre a guerra pipocavam diariamente nos

15 Archivo General de la Administración, DOCUMENTAÇÃO (10)013.001, CAIXA 54-4989, Sociedades españolas 1932. Reglamento del Comité Auxiliar de La Sociedad Agricola e Industrial "La Luz” de Los Tres Rivartemes em Rio de Janeiro (1929). 
principais jornais e revistas ilustradas daquela época, os registros diplomáticos e policiais eram mantidos em segredo e cadastrados como assunto de segurança nacional. Tratava-se, na maioria das vezes, de vigilância e repressão ao comunismo, interpretado como o vilão do conflito na Espanha (2018: 368).

Um acontecimento importante nesse período, na década de 1940, foi o fechamento do Centro Galego do Rio de Janeiro pela ditadura de Getúlio Vargas, o único centro galego das Américas que deixou de existir (Sarmiento, 2014). Temos, nessa conjuntura, duas situações que motivaram o ocorrido: a primeira o fato da ditadura brasileira ter nacionalizado as instituições estrangeiras e proibido a atuação de sociedades com fins políticos; o segundo, que não deixa de estar vinculado à primeira situação exposta, o próprio perfil e histórico do Centro Galego, que se caracterizava por ser uma associação com muitos de seus sócios simpatizantes do movimento operário e de tendências esquerdistas.

Vale ressaltar que na década de 1940 seus sócios se dividiram entre "republicanos" y "nacionalistas", disputa que custou o fechamento do Centro. Toda esta tradição nos leva a crer no temor que viveram as micro associações, contemporâneas à Guerra Civil espanhola que se iniciava, por um lado, com toda a sua polarização política e ideológica e, por outro lado, o novo governo brasileiro que já mostrava seu perfil autoritário. Devemos levar em consideração que os sócios das microssociedades galegas também estavam envolvidos com o Centro Galego, a associação mais importante da coletividade. Por exemplo, a Sociedade Agrícola e Industrial La Luz de los Tres Rivartemes possuia a sua sede no Centro Galego do Rio de Janeiro.

Segundo Tucci Carneiro:

O governo de Getúlio Vargas (1930-1945) justificava sua permanência no poder, sob a alegação de que tentava impedir que o Brasil vivenciasse uma guerra civil, arquitetada pelos comunistas que já haviam se manifestado no Levante de 1935. Por outro lado, essa mesma Guerra Civil servia também aos antifascistas que, organizados em diferentes frentes, investiam contra a política coercitiva de Getúlio Vargas e de Franco (2018: 368).

Dessa forma, seguindo, ainda, os argumentos de Tucci Carneiro, ficava evidente que a neutralidade propagada pelo governo brasileiro era falsa pois, nos bastidores, Vargas identifica-se com as propostas dos regimes nazifascistas e nacionalistas em voga na Europa, que encontravam adeptos no Brasil. Vargas não ocultava seu apoio ao franquismo, representado pela 
Embaixada da Espanha no Brasil e pelo Centro Espanhol Nacionalista, sediado em Porto Alegre. Em vários momentos, Vargas aproveitou-se das notícias sobre a Guerra Civil Espanhola publicadas pela grande imprensa brasileira para justificar a vigilância e a repressão aos comunistas no Brasil que, segundo versão oficial, identificavam-se com a causa dos republicanos espanhóis (Tucci Carneiro, 2018: 368-369).

No caso da Argentina, no mesmo período, o contexto político local também afetou as decisões e o cotidiano de muitas das associações galegas sediadas em Buenos Aires. No dia 15 de maio de 1939, o Decreto $N^{\circ} 31.321$, firmado pelo presidente Roberto Ortiz pretendia regular as atividades das associações estrangeiras com o objetivo de restringir as atividades de ordem política que as entidades viessem a realizar. Um bom exemplo disso, nos oferece o estudo realizado sobre o Centro de Betanzos, que segundo a sua autora, Denise Rocío Ganza, mediante o novo decreto, evitou incluir entre os seus objetivos referências explícitas sobre sua identidade política. As associações que mantivessem finalidades culturais, artísticas ou de assistência social tinham a sua liberdade garantida pelo governo argentino (Ganza, 2014: 155).

A Guerra Civil espanhola, segundo grande parte dos especialistas, politizou de forma crescente as associações e as dividiu, de forma geral, entre republicanos e simpatizantes de Franco. A polarização encontra-se, de um lado, nas grandes instituições espanholas, alinhadas com o regime franquista, e, de outro, nas pequenas sociedades de base comarcal e paroquial, e também, nos Centros Galegos que se posicionavam favoráveis à II República (Fernández Santiago, 2001: 81). Claro está que esta regra não pode ser validada para todos as associações, já que no caso do Centro Galego do Rio de Janeiro as divisões internas entre republicanos e nacionalistas acabaram chamando a atenção do governo de Getúlio Vargas, provocando o fechamento da instituição.

Outros estudos envolvendo as microassociações galegas em Buenos Aires também alertam sobre o impacto da Guerra Civil na vida do tecido associativo, como por exemplo as práticas de solidariedade geradas pelo conflito. É o caso da investigação realizada por Alejandra Noemi Ferreyra, que tomou como recorte espacial o distrito de Porriño, pertencente à província de Pontevedra. A autora destaca o forte compromisso político e ideológico assumido pelas instituições microterritoriais para reunir recursos econômicos com o intuito de socorrer o governo republicano (Ferreyra, 2014: 132)

No caso da coletividade galega no Rio de Janeiro, deparamo-nos com situações de conflito, envolvendo intrigas entre o governo republicano 
espanhol e o brasileiro. Toda a colônia espanhola, inclusive as microassociações galegas se viram envolvidas após o governo brasileiro receber um telegrama dirigido por Deputados da Frente Popular Espanhola ao Presidente da República do Brasil, no caso Getúlio Vargas, censurando medidas internas de repressão ao comunismo. O telegrama, cujo conteúdo saiu nos principais periódicos cariocas, provocou uma situação delicada e perigosa para a colônia espanhola do Rio de Janeiro. O Departamento Nacional de Propaganda do governo de Getúlio Vargas enviou para toda a imprensa o conteúdo do telegrama.

Madrid, 25- Deputados Frente Popular Hespanhola exigimos com grande energia que o processo Capitão Prestes, chefe Alliança Nacional Libertadora, seja público e possa escolher os advogados que entender. Exigimos a sua liberdade e de todos os presos políticos. ${ }^{16}$

As opiniões dos jornais da época se dividem entre os que acreditam na veracidade do documento e pedem providências por parte do governo brasileiro por ferir a sua soberania, e aqueles que duvidam de sua autenticidade. $\mathrm{O}$ Diário de noticias encontra-se no primeiro grupo, os que compunham os indignados com o conteúdo do telegrama e pela audácia dos deputados espanhóis em exigirem semelhante ação do governo brasileiro. A começar pelo título da matéria "Os comunistas hespanhos fazem insolentes exigências ao governo brasileiro”. Em seguida, o periódico descreve a situação da Espanha e seus conflitos internos, não poupando fortes adjetivos para descrever a situação do país:

Todos conhecemos a situação interna hespanhola. Ali, em temas e subterrânea infiltração, excluindo, por vezes, como nas sedições da Catalunha, em sangrentas carnificinas de irmãos, a onda vermelha nutrida com o ouro arrancado ao povo russo espraiou-se até o Parlamento, donde nos vem agora a insolência de telegrama que abaixo transcrevemos. Poucas vezes o delírio tem de tal modo empolgado e obscurecido a consciência de homens públicos que os arraste ao desprimor e é irresponsabilidade de pretenderem intervir com um desembaraço que raia ao insulto nos negócios particulares de uma nação. ${ }^{17}$

Para concluir, o Diário de notícias exige uma atitude do governo brasileiro:

16 Archivo General de la Administración, DOCUMENTAÇÃO (10)013.001, CAIXA 54-5002, Sociedades españolas 1936, Diario de Notícias, 26/5/1936, s/p. 
O telegrama abaixo, incrivelmente verdadeiro, dispensa commentarios, mas exige immediato e enérgico protesto do governo brasileiro contra semelhante insulto à soberania nacional. ${ }^{18}$

Outros periódicos fizeram eco do conflito, apresentando a situação de caos em que se encontrava a Espanha, às vésperas do início da Guerra Civil, incapaz de tomar as rédeas do próprio destino:

O telegrama é subscripto por sessenta Deputados, figurando em primeiro lugar o Sr. Largo Caballero, chefe do Partido Comunista da Hespanha.

A arrogância contida na exigência final do telegrama seria um motivo de pilheria se não contivesse em si mesma e attestado da triste e dolorosa situação a que deve estar reduzida a pobre Hespanha com a espécie de gente que resolve hoje dos seus destinos. ${ }^{19}$

Já o periódico Correio da Manhã duvidou da autenticidade do documento e justificou a sua posição:

Publicamos o telegrama acima, por dever profissional. Não acreditamos, porém, na sua autenticidade. Elle é tão absurdo, que não pode ser verídico e justamente não o pode ser pelos nomes que o subscrevem. Estadistas que vem tomando parte nos negócios políticos da Hespanha, que não é um país inculto, seria o cumulo que commettessem semelhante "gaffe".

O telegrama foi subscripto por sessenta Deputados, figurando em primeiro lugar o Sr. Largo Caballero, chefe do Partido Comunista da Hespanha. No ano de 1939, já com a vitória do franquismo e com a ditadura no Brasil, as perseguições aos galegos, principalmente aos destacados líderes das associações, começaram a acontecer, tanto de parte do governo espanhol como do brasileiro. ${ }^{20}$

Autêntico ou não, o fato é que após a divulgação do telegrama na imprensa brasileira, a coletividade espanhola do Rio de Janeiro viu-se envolvida

18 Archivo General de la Administración, DOCUMENTAÇÃO (10)013.001, CAIXA 54-5002, Sociedades españolas 1936, Diario de Notícias, 26/5/1936.

19 Archivo General de la Administración, DOCUMENTAÇÃO (10)013.001, CAIXA 54-5002, Sociedades españolas 1936, Jornal do Comercio, 25/5/1936 
em um conflito de estado. A Diretoria da Câmara Oficial Espanhola de Comércio e Indústria do Rio de Janeiro examinou o telegrama publicado a pedido do Departamento Nacional de Propaganda e concluiu: "sem discutir a existência legal do telegrama, devido a sua origem, expressamos nosso receio sobre a autenticidade dos nomes, pela responsabilidade assumida". ${ }^{21}$ Para amenizar o conflito, a colônia espanhola escreveu uma carta, dirigida ao presidente Getúlio Vargas, desculpando-se pela intempérie.

A Colônia espanhola vem testemunhar a V.E. junto com a nossa admiração pelas suas virtudes de governante, a nossa sincera compreensão da sua simpatia pela Espanha e pelos espanhóis aqui residentes, afecto profundamente correspondido por quantos dedicamos a esta grande Nação o melhor de nossas actividades, considerando-as como nossa segunda Pátria ${ }^{22}$

O teor da carta demonstra a preocupação da coletividade espanhola do Rio de Janeiro em "desatar o nó" que surgiu de um telegrama de fundo duvidoso, mas que desagradava parte da imprensa brasileira e, por suposto, desafiava as autoridades governamentais, num contexto, como já explicamos linhas acima, de perseguição aos comunistas. Os imigrantes espanhóis, galegos, residentes na sociedade carioca, já possuíam na década de 1930 uma antiga tradição migratória, inserção no comércio da cidade e lideranças que demonstravam a visibilidade através da credibilidade de suas associações e de sua trajetória profissional. Trata-se de homens de negócio como os que pertenciam à Diretoria da Câmara Oficial Espanhola de Comércio e Indústria do Rio de Janeiro. ${ }^{23}$ Não haveria uma elite intelectual, como afirmou alguns historiadores, mas tratava-se de uma imigração consolidada, majoritariamente formada por imigrantes originários da Galícia e com importância econômica na sociedade carioca.

Por último, importa mencionar a representação geográfica das associações galegas. Grande parte das microassociações do Rio de Janeiro são formadas por sócios naturais da província de Pontevedra, de municípios com importantes fluxos migratórios, como os casos dos municípios de Tomiño e Arbo, por citar alguns exemplos. Isso corrobora com a tese de que a fundação

21 Archivo General de la Administración, DOCUMENTAÇÃO (10)013.001, CAIXA 54-5002, Sociedades españolas 1936.

22 Archivo General de la Administración, DOCUMENTAÇÃO (10)013.001, CAIXA 54-5002, Sociedades españolas 1936, Correio da Manhã, 26/5/1936.

23 Ao se priorizar as microassociações galegas no presente artigo, não trataremos destas lideranças étnicas que faziam parte de associações comerciais ou de âmbito nacional, que já compunham uma elite econômica na sociedade carioca. 
das associações se deu a partir de cadeias migratórias já estabelecidas, reproduzindo os fluxos migratórios dos galegos no Rio de Janeiro. Para este estudo em específico, vale ressaltar que essa tese se aplica perfeitamente, pois a província de Pontevedra, além de se apresentar como a mais importante no que diz respeito a quantitativo migratório a Rio de Janeiro é, também, a que possui maior número de municípios, de todas as províncias galegas, com fluxos intensos a esta cidade (Sarmiento, 2017). Em suma, no momento de formação dessas microassociações nas primeiras décadas do século XX, podemos concluir que já havia uma imigração consolidada dos municípios pontevedreses.

\section{Reflexões finais}

A partir da análise de novas fontes para o caso do associativismo galego no Rio de Janeiro, foi- nos revelado que as associações microterritoriais mantiveram participação ativa junto à comunidade espanhola, sendo de momento as únicas existentes nessa análise de escala, no Brasil. Vale mais, neste caso, pensar no qualitativo dessa imigração do que em seu quantitativo para extrair algumas conclusões. Podemos dizer, que, ainda que em muito menor medida que no caso argentino, o associativismo galego no Rio de Janeiro também se distinguiu pelo surgimento de várias instituições de âmbito microterritorial, que apresentavam como espaço de referência as divisões geográfico-administrativas da Galícia, inferiores à província, como o município ou até mesmo a paróquia. Muitos desses sócios circulavam em diferentes espaços, assumindo lideranças junto com as redes migratórias, que lhe abriram possibilidades de ascensão social tanto na sociedade receptora como na de origem. As microassociações apresentadas, criadas nas primeiras décadas do século XX, todas originárias de municípios da província de Pontevedra confirmam a presença de uma coletividade exponencial da província com maior representação migratória no Rio de Janeiro.

A documentação, pautada na década de 1930, demonstrou a sobrevivência das microassociações, através das correspondências consulares, em um período conflitivo para os imigrantes espanhóis tanto na sociedade de recepção quanto na de origem. Por um lado, viviam a vigilância aos estrangeiros e a perseguição aos comunistas pelo autoritário governo de Getúlio Vargas, e, por outro, o fim da Segunda República espanhola e o início da Guerra Civil.

O silêncio dessas micro sociedades, a partir da década de 1940, em meio aos conflitos internacionais e submersas em governos autoritários, talvez 
também possa ser atribuído à não sobrevivência das mesmas à complexidade da cidade e da produção do espaço urbano. Somando-se a isso, poderíamos propor, também, a complexidade própria da constituição histórica e geográfica dos diversos grupos e na sua relação - via de regra bastante tensa - com as estruturas sociais, espaciais, culturais e políticas de um momento turbulento. Devemos pensar na cultura política desses galegos, suas prioridades e estratégias de sobrevivência em um mundo prestes a ser polarizado. 


\section{O Bibliografia}

»Blanco, J. A. (2008). El asociacionismo en la emigración española a América. Salamanca: Uned.

"Díaz, H. M. (2011). Perfil sociodemográfico e redes familiares nunha asociación comarcal galega. En: Cristóforis, Nadia (coords.). Baixo o signo do franquismo: Emigrantes e exiliados galegos na Arxentina (pp. 163-185). Santiago de Compostela: Sotelo Blanco Edicións.

»Farías, R. (2011). El asociacionismo gallego en Buenos Aires y las posibilidades que ofrece para el estudio de la integración de los migrantes: Un análisis a partir del archivo de la FAGA-MEGA. Antíteses, 4(7), 151-171.

»Fernández Santiago, M. X. (2001). Associacionismo gallego en Buenos Aires (1936-1960). Em X. M. Núñez Seixas (ed.), La Galicia Austral. La inmigración gallega en la Argentina (pp. 181-202). Buenos Aires: Biblos,

"Fernández, A. (2011). Historiografía das asociacións galegas: o caso arxentino e algunas comparacións latinoamericanas. En: N. Cristóforis (coord.), Baixo o signo do franquismo: emigrantes e exiliados galegos na Arxentina (pp. 141-162). Santiago de Compostela: Sotelo Blanco Edicións.

»Fernández, A. y Moya, J. C. (eds.) (1999). La inmigración española en la Argentina. Buenos Aires: Biblos.

»Ferreyra, A. N. (2014). Una comarca emigrada galega frente a los avatares políticos en la sociedad de partida. En: N. Cristóforis \& M. I. Tato (eds.), Las grandes guerras del siglo XX y la comunidade española de Buenos Aires (pp. 109-135). Ciudad Autônoma de Buenos Aires: Editorial de la Facultad e de Filosofía y Letras Universidad de Buenos Aires.

» Gallego, A. M. (1995). Espanhóis. São Paulo: CEM.

»Ganza, D. R. (2014). Una comarca emigrada galega frente a los avatares políticos en la sociedad de partida. En: N. Cristóforis \& M. I. Tato (eds.), Las grandes guerras del siglo XX y la comunidade española de Buenos Aires (pp. 137-166). Ciudad Autônoma de Buenos Aires: Editorial de la Facultad e de Filosofía y Letras Universidad de Buenos Aires.

»González Martínez, E. (2008). La práctica asociativa de los españoles en Brasil. En: J. A. Blanco (ed.). El asociacionismo en la emigración española a América. Salamanca: Uned.

»González Martínez, E. (2018). Asociaciones españolas en Brasil. En: A. Mateos (coord.), Los españoles em América (pp. 219-266). Madrid: Editorial Eneida.

» Jorge, N. (2004). As Escolas indianas en Tomiño. Revista de novos investigadores, 10.

» Maciel, L. A. y Antonacci, M. A. M. (1997). Os españóis en São Paulo: Cultura, cotián e experiencias de vida. Estudios Migratorios, 3, 65-111.

" Moya, J. C. (2004). Primos y extranjeros. La inmigración española en Buenos Aires, 1850-1930. Buenos Aires: Emecé. 
»Núñez Seixas, X. M. (1998). Emigrantes, caciques e indianos. O influxo sociopolítico da emigración transoceánica en Galicia (1900-1930). Vigo: Xerais.

» Núñez Seixas, X. M. (200). Redes sociales e asociacionismo: Las paroquias gallegas de Buenos Aires (1904-1936). Estudios Interdisciplinarios de América Latina y Caribe, 11(1), 23-43.

"Sánchez Alonso, B. (1992). Las causas de la emigración española (18801930). Madrid: Alianza.

"Sarmiento, E. (2014). Elementos prejudiciais: O fechamento do Centro Galego no Rio de Janeiro pelo governo Vargas. En: M. A. G. Vianna, E. Sarmiento \& L. P. Gonçalves (orgs.), Presos políticos e perseguidos estrangeiros na Era Vargas (pp. 111-128). Rio de Janeiro: Mauad/FAPERJ.

»Sarmiento, E. (2017). Galegos nos trópicos: Invisibilidade e presença da imigração galega no Rio de Janeiro (1880-1930). Porto Alegre: EdiPUCRS.

»Sarmiento, E. (2018). Aproximações da emigração galega no Rio de Janeiro e em Buenos Aires por meio do estudo comparado. Historiografia e associativismo étnico na Grande Imigração. Revista do Instituto Histórico e Geographico Brazil, (II)487, 107-130.

» Tucci Carneiro, M. L. (2018). As marcas do impacto. Narrativas e representações da Guerra Civil Espanhola. En: H. Gutiérrez. [et al.] (Orgs.). A guerra civil espanhola e a América Latina [recurso eletrônico]. São Paulo: PROLAMEPAL/USP: CEDHAL/USP: ECA-USP, Terceira Margem. 
